\title{
Effect of Body Mass Index on Pregnancy Outcomes in Nulliparous Women Delivering Singleton Babies: Observational Study
}

\author{
Jain Deepika $\cdot$ Khuteta Rakesh $\cdot$ Chaturvedi Veena \\ Khuteta Sushila
}

Received: 12 April 2011/Accepted: 4 June 2012/Published online: 1 August 2012

(C) Federation of Obstetric \& Gynecological Societies of India 2012

\begin{abstract}
Objective To find out the effect of increasing body mass index (BMI) on pregnancy outcomes in nulliparous women delivering singleton babies.

Method This was a hospital-based observation study, based on 300 nulliparous women delivering singleton babies in June 2009-Sept. 2010. Women were categorized into three groups. Underweight (BMI $<20 \mathrm{~kg} / \mathrm{m}^{2}$ ), normal (BMI 20$24.9 \mathrm{~kg} / \mathrm{m}^{2}$ ), overweight (BMI $25-29.9 \mathrm{~kg} / \mathrm{m}^{2}$ ), and obese (BMI $>30 \mathrm{~kg} / \mathrm{m}^{2}$ ) obstetric and perinatal outcomes were compared by univariate and multivariate analysis.

Results Maximum patients who underwent LSCS were having BMI $>30 \mathrm{~kg} / \mathrm{m}^{2}$ [OR 9.558 (95\% CI 5.82-17.27)]. As compared to women of normal BMI $\left(20-24.9 \mathrm{~kg} / \mathrm{m}^{2}\right)$, morbidly obese women faced the higher risk of PIH [OR 8.045 (95 \% CI 3.875-16.781)]. Obese women were more likely to have post partum hemorrhage [OR 5.11 (95\% CI 1.76-14.79)] compared with women of normal BMI. Birth weight $<2,500 \mathrm{~g}$ was more common in women with BMI $<25 \mathrm{~kg} / \mathrm{m}^{2}(21.21 \%)$, while highest incidence of
\end{abstract}

Jain D., P.G. Student · Khuteta R., Professor ·

Chaturvedi V., Medical Officer - Khuteta S., Assistant Professor

Department of Obstetrics and Gynaecology,

Mahila Chikitsalaya, S.M.S. Medical College,

Jaipur 302001, Rajasthan, India

Jain D. ( $\square)$, P.G. Student

Pramod Singvi C/o Dr. M.D. Singvi, Flat No. 104, Suraj Deep

Apartment, Ramdas Peth, Akola 444001, Maharashtra, India

e-mail: deepika_mgnims@yahoo.co.in birth weight $>4,000 \mathrm{~g}(14.29 \%)$ is seen in women of the obese group.

Conclusions Increasing BMI is associated with increased incidence of cesarean delivery, PIH, post partum hemorrhage, and macrosomic babies.

Keywords Body mass index $\cdot$ PIH $\cdot$ LSCS $\cdot$ PPH · Birth weight

\section{Introduction}

The problem of rising obesity is not unique to India; WHO data shows that at least 2.6 million people die each year as a result of being overweight or obese, which makes obesity a bigger killer than malnutrition. Body mass index (BMI) - the weight in kilograms divided by the square of the height in meters $\left(\mathrm{kg} / \mathrm{m}^{2}\right)$-is used to classify overweight and obesity in adults.

In earlier research, the relationship between maternal height and weight with pregnancy complications was extensively explored, but in recent times, BMI is widely accepted as a better measure of over or underweight [1].

The studies conducted so far are from western developed countries and there is a paucity of data from developing countries [2].

The aim of this study was to examine the association between BMI and obstetric and perinatal outcomes in primigravid women delivering singleton babies. 


\section{Method}

The study protocol was approved by the Regional Committee for Medical Research Ethics and all participants gave informed written consent.

This study was an observation study conducted in the Department of Obstetrics \& Gynecology, SMS Medical College, Jaipur from July 2009 to August 2010 on 300 nulliparous women with singleton term pregnancies who were in early labor. Women with multi fetal gestation, congenital malformation, and pregnancy with known medical disorder were excluded from the study.

All anthropometric measurements (weight and height) were carried out by means of standard methodology as described by Lohman et al. [3]. These women were followed till delivery. New born baby weight was taken at the time of birth without any clothes. To remove inter observer bias and instrumental bias, all measurements were taken by the same measuring instrument/scale and by same person.

BMI was calculated by means of the formula weight/ height ${ }^{2}$. Women were categorised into 4 groups [4].

$$
\begin{aligned}
& \text { Underweight } \leq \text { BMI of } 19.9 \mathrm{~kg} / \mathrm{m}^{2} \\
& \text { Normal-BMI } 20-24.9 \mathrm{~kg} / \mathrm{m}^{2} \\
& \text { Overweight-BMI } 25-29.9 \mathrm{~kg} / \mathrm{m}^{2} \\
& \text { Obese-BMI }>30 \mathrm{~kg} / \mathrm{m}^{2}
\end{aligned}
$$

The group with BMI in the normal range $\left(20-24.9 \mathrm{~kg} / \mathrm{m}^{2}\right.$ ) was used as the reference or comparison group for the analysis.

Obstetric outcomes included the following-PIH, mode of delivery, $\mathrm{PPH}$, and perinatal outcomes in form of birth weight were assessed.

Statistical analyses were conducted, continuous characteristics of samples were expressed in mean \pm standard deviation, and categorical outcomes were compared by Chi-square test and odds ratio with $95 \%$ confidence interval. A $p$ value of $<0.05$ was regarded as statistically significant.

\section{Results}

A total of 300 women were included in the study. In this, 10 were $(3.3 \%)$ underweight, 193 (61\%) had normal BMI, 71 (24\%) were overweight, and 17 (6\%) were obese. The mean age of the study group was $22.94 \pm$ 3.04 years. The following results showed the incidence of complication of pregnancy; labor and delivery in women in different BMI categories.

$\mathrm{PIH}$ increased linearly with increasing BMI, resulting in odds ratio of 8.045 (95\% CI 3.875-16.781) in the morbidly obese categories compared to those of normal BMI. The risk of cesarean section was more common in the morbidly obese group [odds ratio $9.558 \quad(95 \%$ CI 5.828-17.271)] compared to the normal BMI group, while in the underweight women group, all had normal vaginal delivery. The risk of postpartum hemorrhage remained statistically significant in BMI $>30 \mathrm{~kg} / \mathrm{m}^{2}$ (odds ratio 5.112 (95\% CI 1.767-14.793) compared to the normal BMI group.

Low birth weight (birth weight $<2,500 \mathrm{~g}$ ) was more common in underweight women $(80 \%)$ compared to the women with BMI $20-25 \mathrm{~kg} / \mathrm{m}^{2}(21.21 \%)$ [odds ratio $0.32(95 \%$ CI 0.180-0.568)]. Macrosomia (birth weight $>4,000 \mathrm{~g}$ ) was more common in women with BMI > $25 \mathrm{~kg} / \mathrm{m}^{2}$ (15\%), while no macrosomic baby was delivered in the normal BMI group (Tables 1, 2).

\section{Discussion}

This study adds to the increasing body of evidence which suggests that obesity measured by BMI predisposed women to complicated pregnancy and increased obstetric interventions.

A meta analysis of the risk of PIH associated with maternal BMI showed that the risk of preeclampsia doubled with each $5-7 \mathrm{~kg} / \mathrm{m}^{2}$ increase in pre-pregnancy BMI [4]. Our study found an eight times higher risk of PIH in obese women $\left(\mathrm{BMI}>25 \mathrm{~kg} / \mathrm{m}^{2}\right)$.

This study observed that maximum women who underwent LSCS were overweight (54.32\%) and obese $(61.90 \%)$; this was in accordance with Sohinee Bhattacharya in 2007 [1] and another study [5].

In this study, the maximum occurrence of $\mathrm{PPH}$ $(14.29 \%)$ was highest in the BMI group $>30 \mathrm{~kg} / \mathrm{m}^{2}$. Many studies have reported conflicting results; Sohinee Bhattacharya [1] and Sebire et al. [6] observed an increase in PPH with an increase in BMI. Bianco et al. [7] found no such difference in the incidence as measurement of blood loss is subjective and definition of post partum hemorrhage variable.

The risk of low birth weight was more in underweight women, while macrosomia was more common in overweight and obese women. These results were in accordance with several studies investigating the relationship of

Table 1 Study sample characteristics

\begin{tabular}{lrll}
\hline Parameters & \multicolumn{1}{l}{ Mean } & Std. deviation & $N$ \\
\hline Age (years) & 22.9467 & 3.04874 & 300 \\
Weight $(\mathrm{kg})$ & 57.5000 & 8.28162 & 300 \\
Height $(\mathrm{cm})$ & 153.1900 & 8.46479 & 300 \\
BMI $\left(\mathrm{kg} / \mathrm{m}^{2}\right)$ & 24.6181 & 3.69523 & 300 \\
Birth weight $(\mathrm{kg})$ & 2.8245 & 0.56481 & 300 \\
\hline
\end{tabular}


Table 2 Association of obstetric and perinatal outcomes with body mass index

\begin{tabular}{lcllll}
\hline Outcomes & $\begin{array}{l}\text { Under weight } \\
\mathrm{BMI} \leq 19.9 \mathrm{~kg} / \mathrm{m}^{2} \\
n=10\end{array}$ & $\begin{array}{l}\text { Normal } \\
\text { BMI-20-24.9 kg/m } \\
n=188\end{array}$ & $\begin{array}{l}\text { Overweight }+ \text { obese } \\
\text { BMI } \geq 25 \mathrm{~kg} / \mathrm{m}^{2} \\
n=102\end{array}$ & $\begin{array}{l}p \text { value } \\
\text { Odds ratio 95 of OR }\end{array}$ \\
\hline PIH & - & $11(5.56 \%)$ & $34(33.33 \%)$ & $<0.001$ & $9.558[5.828-17.27]$ \\
LSCS & - & $22(11.70 \%)$ & $57(55.88 \%)$ & $<0.001$ & $8.045[3.875-16.781]$ \\
PPH & - & $5(2.66 \%)$ & $13(12.75 \%)$ & $<0.001$ & $5.112[1.767-14.793]$ \\
LBW & $8(80 \%)$ & $34(18.09 \%)$ & $32(31.37 \%)$ & 0.055 & $0.32[0.180-0.568]$ \\
Macrosomia & - & - & $15(14.71 \%)$ & 0.002 \\
\hline
\end{tabular}

\section{Distribution of obstetric and perinatal outcomes with Body Mas Index}

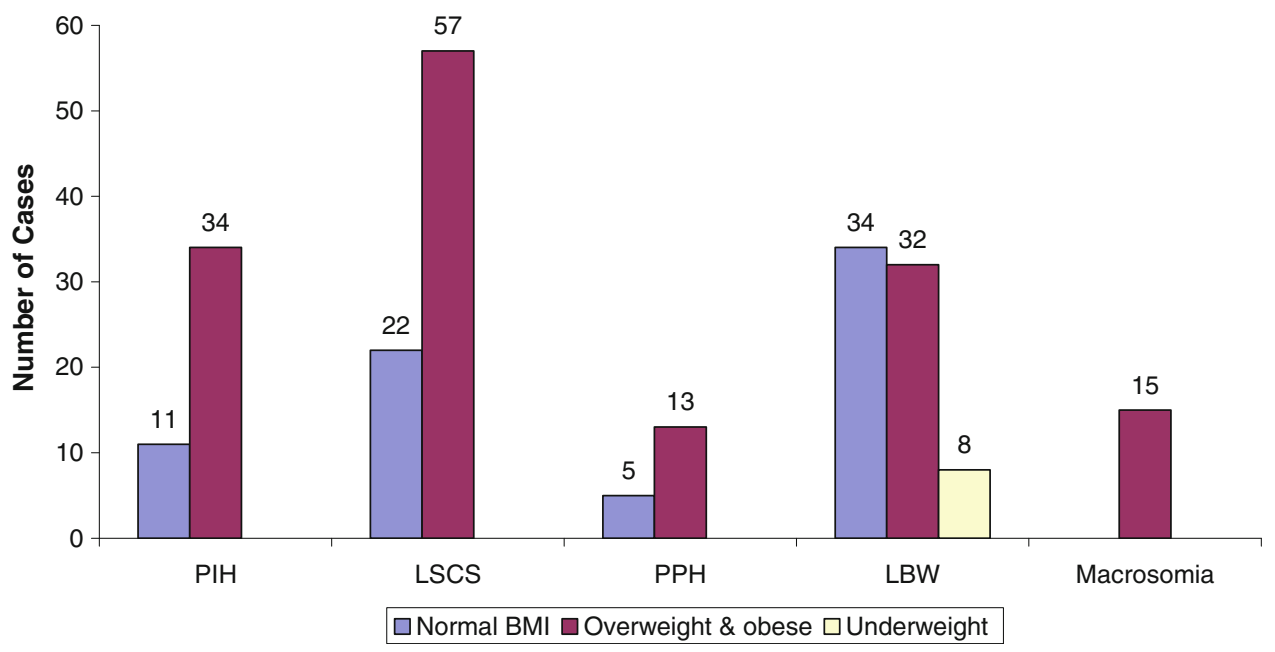

maternal obesity with fetal growth, which showed that obese women have an 18-26\% increased chance of delivering large of date infants $[6,8]$.

\section{Conclusion}

This study has shown an association between maternal overweight and obesity and adverse pregnancy outcomes including PIH, higher cesarean section rate, fetal macrosomia and PPH.

There is also the need to develop guidelines on weight gains to optimize pregnancy and neonatal outcomes. It is recommended that further studies involving large samples comparable to those done in Western countries are carried out.

Acknowledgments The authors first and foremost thank the women who participated in this study. We thank Dr. Subhash Nepalia, Principal of the Institute, who allowed us to conduct the study in his institute. We would like to thank Dr. Rajeev Yadav for his contribution in statistical analysis.

\section{References}

1. Bhattacharya S, Campbell DM, Liston WA, et al. Effect of body mass index on pregnancy outcomes in nulliparous women delivering singleton babies. BMC Public Health. 2007;7:168.

2. Sahu MT, Agrawal A, Das V, et al. Impact of maternal body mass index on obstetric outcome. J Obstet Gynaecol Res. 2007;33: $655-9$.

3. Lohman TG, Roche AF, Martorell R. Anthropometric standardization reference manual. Champaign: Human kinetics Book; 1988.

4. O' Brien TE, Ray JG, Chan WS. Maternal body mass index and the risk of preeclampsia: a systemic review. Epidemiology. 2003; $14: 368-74$

5. Cedergren MI. Maternal morbid obesity and the risk of adverse pregnancy outcome. Obstet Gynecol. 2004;103:219-24.

6. Sebire NJ, Jolly M, Harris JP, et al. Maternal obesity and pregnancy outcome. A study of 287,213 pregnancies in London. Int J Obes. 2001;25:1175-82.

7. Bianco AT, Smilen SW, Davis Y, et al. Pregnancy outcome and weight gain recommendations for the morbidly obese woman. Obstet Gynecol. 1998;91:97-102.

8. Weiss JL, Malone FD, Emig D, et al. Obesity, obstetric complications and caesarean delivery rate-a population based screening study. Am J Obstet Gynecol. 2004;190:1091-7. 